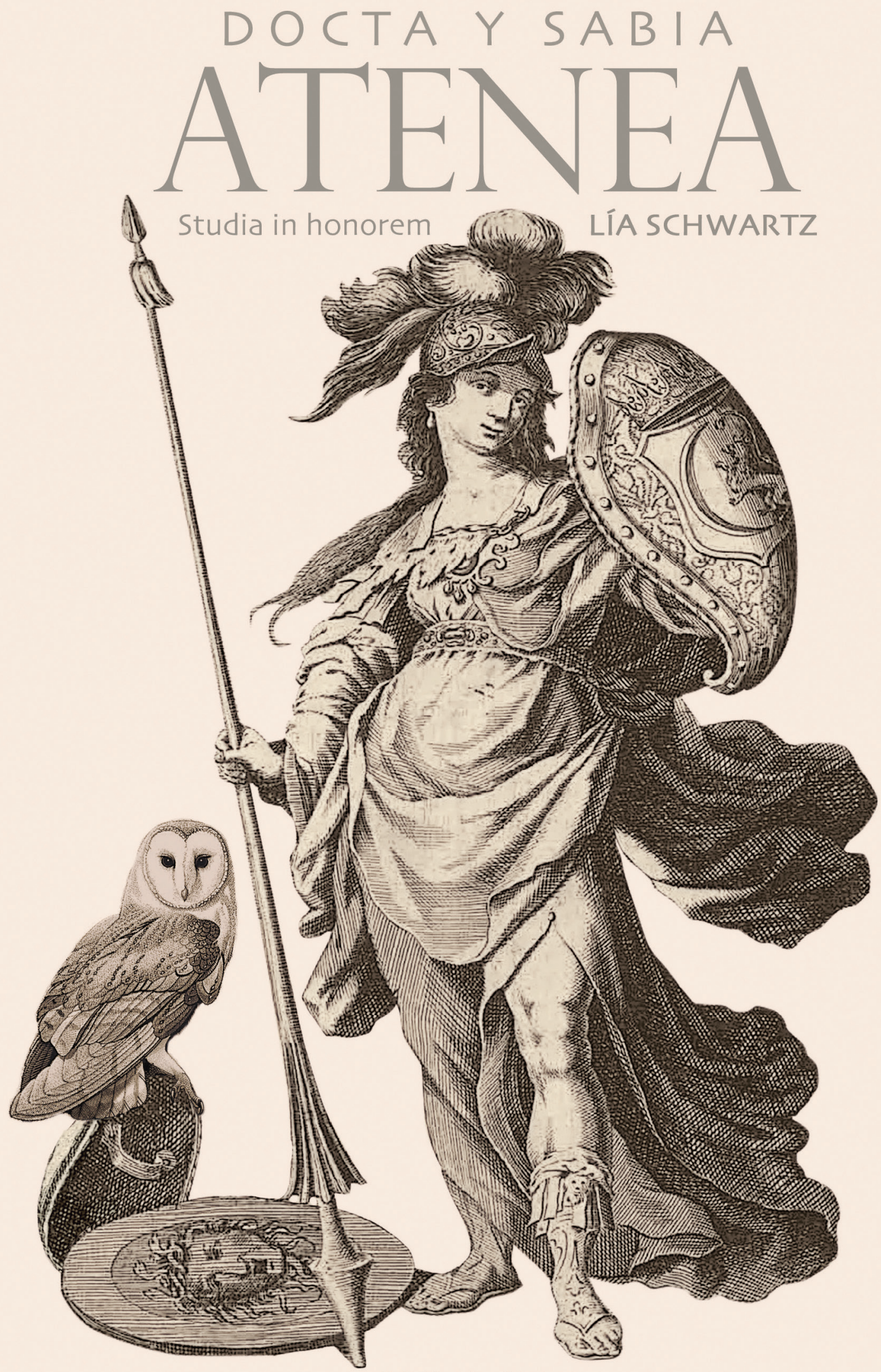

Edición al cuidado de:

SAGRARIO LÓPEZ POZA, NIEVES PENA SUEIRO, MARIANO DE LA CAMPA, ISABEL PÉREZ CUENCA, SUSAN BYRNE Y ALMUDENA VIDORRETA 



\section{DOCTA Y SABIA ATENEA Studia in honorem Lía Schwartz}

Edición al cuidado de:

Sagrario López Poza, Nieves Pena Sueiro, Mariano de la Campa, Isabel Pérez Cuenca, Susan Byrne y Almudena Vidorreta

A Coruña, 2019 

Profesora Lía Schwartz

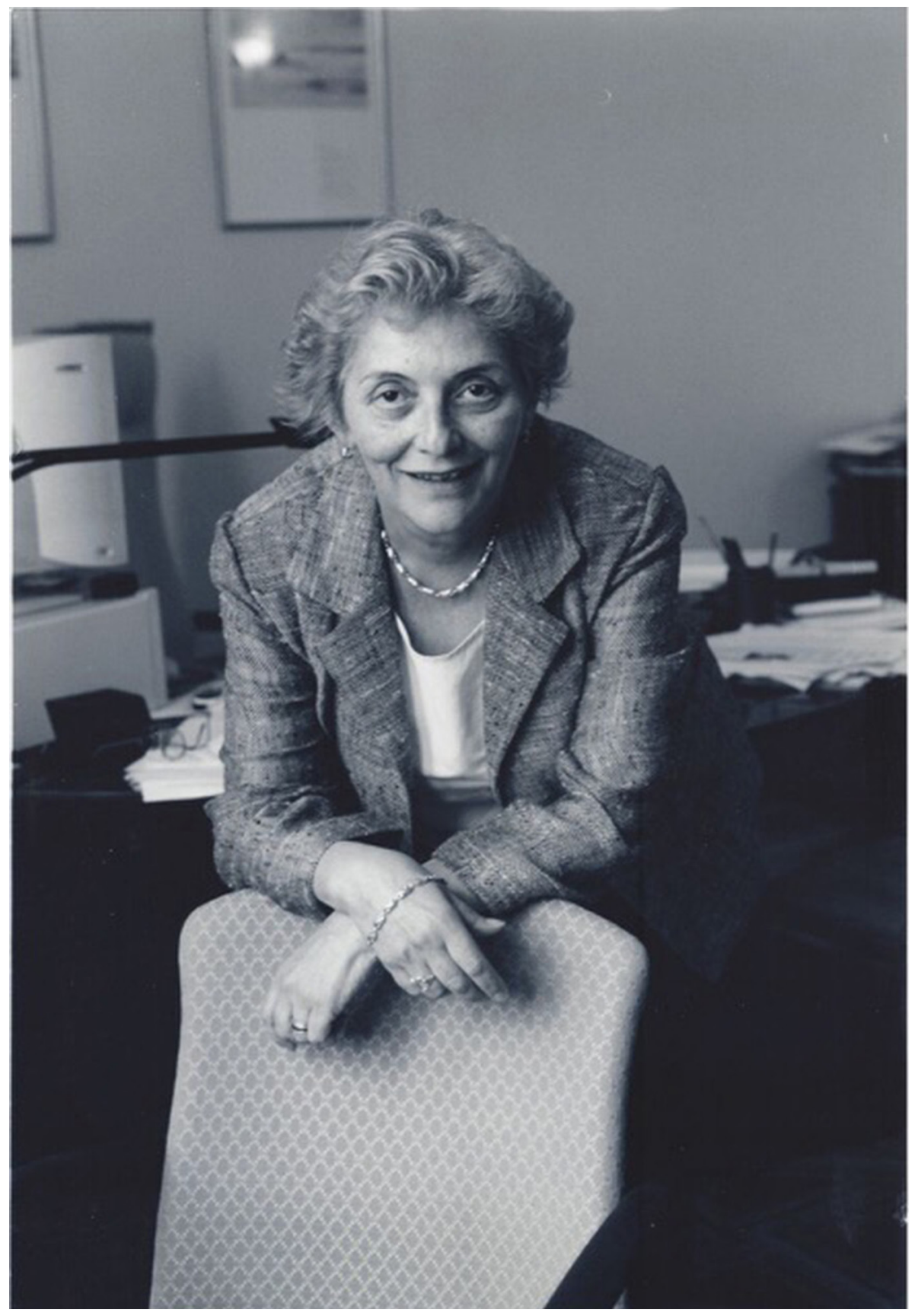


Sagrario López Poza, Nieves Pena Sueiro, Mariano de la Campa, Isabel Pérez Cuenca, Susan Byrne, Almudena Vidorreta (editores)

Docta y sabia Atenea. Studia in honorem Lia Schwartz

N. ${ }^{\circ}$ de páginas: 832

$17 \mathrm{x} 24 \mathrm{~cm}$.

Índice: pp. 7-10

ISBN: 9788497497046

Depósito Legal: C 53-2019

CDU: $821.134 .2(082.2) *$ SCHWARTZ

IBIC: DS | 2ADS | DQ

Editan:

Universidade da Coruña, Servizo de Publicacións

Instituto Universitario "La Corte en Europa" (IULCE), Universidad Autónoma de Madrid

Hispanic Seminary of Medieval Studies (HSMS), New York

Queen Sofía Spanish Institute, New York

Seminario Interdisciplinar para el estudio de la Literatura Áurea Española (SIELAE), Grupo Hispania, Universidade da Coruña

(C) Los autores

(C) De esta edición:

Servizo de Publicacións, Universidade da Coruña

Colección: Homenaxes n. ${ }^{\circ} 14$

Diseño de la cubierta: Paula Lupiáñez (Cirugía Gráfica. Madrid)

Interior: Juan de la Fuente

Impreso en Lugami Artes Gráficas, Betanzos (España)

Printed in Spain 


\section{ÍNDICE}

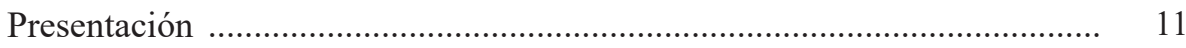

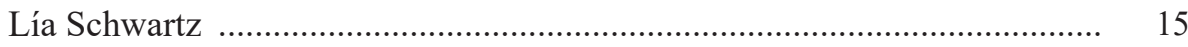

Bibliografía de Lía Schwartz ................................................................. 19

\section{Estudios en homenaje a la profesora Lía Schwartz}

Antonio Azaustre

Notas sobre la filiación en la tradición manuscrita de El alguacil endemoniado

Mercedes Blanco

Para una definición del gongorismo. El caso de Nueva España

69

JAVIER BLASCO

«Salta Pan, Venus baila, Bacho entona»: el campo léxico de la música como vehículo del erotismo en la poesía de los Siglos de Oro

SUSAN BYRNE

La armonía neoplatónica en "A Francisco de Salinas» de fray Luis de León

Mariano de La CAMPa

Poemas de Quevedo en impresos del siglo XVII: Los Romances varios .....

Manuel Ángel Candelas

La poesía española en los manuscritos de la Biblioteca Nazionale di Napoli: noticias y textos

ANTONIO CARREÑo

Lope de Vega: «Rompa ya el silencio el dolor en mí»

Donald CRUickshank

Don Toribio Cuadradillos, «avestruz del amor», and El lindo don Diego (with a note on Quevedo) 
María D'Agostino

Un juego de espejos deformantes. La «representación» del conde de Lemos entre Argensola y Cervantes

TREVOR J. DADSON

«Yo no puedo salir del trabajo de parecer a los portugueses castellano y a los castellanos portugués»: Diego de Silva y Mendoza y la poesía hispanoportuguesa de principios del siglo XVII

Ottavio Di Camillo

Of Roasted Eggs and Other Issues in the Celestina

Aurora EGIDO

Retórica y poética de los afectos en el soneto XIV de Garcilaso 265

Santiago Fernández Mosquera

El vicio de la virtud en Los trabajos de Persiles y Sigismunda 283

Flavia Gherardi \& Pedro Cátedra

El Discorso in difesa della poesia de Gian Ambrogio Biffi en el ámbito de la poética italiana y española

AdRIÁN M. IZqUiERDO

Paráfrasis y experimentación poética en el Anacreón castellano de Quevedo

HILAIRE KALLENDORF

Splitting Hairs or Finding Threads: The Labyrinth as Metaphor for Moral Dilemma in the Comedia

José ENRIQUE LAPLANA

La erudición en el Para todos de Juan Pérez de Montalbán

Begoña LóPEZ Bueno

El Ramillete de las Musas Castellanas (Bibliothèque Mazarine, ms. 4047): un canon literario español en el siglo XVII francés. Primera parte

SAGRARIo LóPez PozA

«Amoris vulnus idem sanat, qui fecit». Notas sobre la fortuna de un topos clásico

ISABEL LOZANO RENIEBLAS

El mal latín del episodio de dos falsos cautivos del Persiles 
Alison Maginn

Rubén Darío's Final Chapter: Archer Milton Huntington and the Hispanic Society

Miguel Martínez

Góngora asiático. Notas sobre poesía filipina inédita del primer Barroco ....

José Martínez MiLlán

Isabel Clara Eugenia, ¿una infanta castellana?

Clayton McCarl

Hacia un modelo para el marcado semántico de los textos marítimos de la época colonial

\section{Juan Montero Delgado}

Un soneto desconocido de Pedro Espinosa a Francisco de Rioja en el ms. Span 56 de la Houghton Library (Universidad de Harvard) 561

Nuria Morgado

Pervivencia del Barroco en la poética de la modernidad: intuiciones y conceptos en el pensamiento literario de Antonio Machado

FRANCISCA MOYA DEL BAÑo

La presencia de Plauto en Quevedo

VALENTINA NIDER

El oro como botín en los poemas de Quevedo sobre Belisario (B-267 e

B-281) y el contexto literario hispano-italiano

ISABEL PÉREZ CUENCA

Francisco de Quevedo y Antonio Sancho Dávila y Toledo Colonna, III marqués de Velada

FERnANDo Plata

El sentido de «barranco» en La Perinola de Quevedo y en otros textos del Siglo de Oro 653

José María Pozuelo Yvancos

Interdiscursividad: cine y literatura en Javier Cercas 671

Augustin Redondo

El tema de la mujer caída de una torre abajo: tradiciones culturales (grecolatinas, bíblicas, folklóricas), creencias religiosas y creaciones cervantinas ... 
MANUEl Rivero RODRÍGUEZ

El conde duque de Olivares, mecenas de la Historia y creador de opinión ... 701

MARIE RoIG Miranda

Los Sueños de Quevedo o cierto tipo de novela 723

Melchora Romanos

Séneca en las Anotaciones de Pedro Díaz de Rivas a los poemas mayores de Góngora

JAVIER SAN JosÉ LeRA

La Política de Dios de Quevedo como comentario bíblico: Política, Biblia y Literatura

LuIs SÁNCHEZ LAÍlLA

Ignacio de Luzán y la musa bucólica

Almudena Vidorreta

Teresa de Jesús, precursora de Gabriela Mistral y Alfonsina Storni

JUAN DiEgo VILA

«con las ansias de la muerte»: El aparato prologal del Persiles como programa estético del estilo tardío cervantino 


\title{
«Yo no puedo salir del trabajo de parecer a los portugueses castellano y a los castellanos portugués»: Diego de Silva y Mendoza y la poesía hispano-portuguesa de principios del siglo XVII
}

\author{
Trevor J. DADSON \\ Queen Mary University of London
}

Hace más de cincuenta años, el poeta y crítico literario Luis Rosales escribió un artículo muy importante titulado «La poesía cortesana». En él se propuso mostrar cómo los herederos inmediatos de la poesía de Garcilaso de la Vega no se encontraban en España sino en Portugal, en las personas de Francisco de Sá de Miranda y Luís Vaz de Camões. Mantuvieron viva en sus versos lo que Rosales llamaba «la sensibilidad garcilasiana» hasta que pudo volver a España mediante la poesía de dos nobles: el conde de Villamediana (Juan de Tassis y Peralta) y el conde de Salinas (Diego de Silva y Mendoza). Rosales demostró convincentemente cómo tanto Villamediana como Salinas fueron influidos por, en particular, la poesía de Camões, que conocían muy bien, imitando o parafraseando sonetos suyos o simplemente pasándolos directamente al castellano. Como dijo entonces:

La primera [conclusión] es que existe una fuerte influencia de Garcilaso en Camões, y de Camões en la poesía española del barroco [...]. La segunda es que existe una verdadera comunidad poética hispano-portuguesa durante los siglos quince, dieciséis y diecisiete, comunidad por consiguiente muy anterior a la reunión de ambas coronas [...]. Nosotros añadimos que durante toda la primera mitad del siglo diecisiete se continúa esta comunidad 
formando una verdadera escuela poética cuyos principales representantes entre nosotros fueron el Conde de Salinas, Bartolomé Leonardo de Argensola, el Conde de Villamediana y Lope de Vega. $(1963: 326)^{1}$

La línea de sensibilidad poética, entonces, que va desde Garcilaso de principios del siglo XVI hasta Francisco de Quevedo del XVII, pasó por unos cuantos poetas portugueses antes de volver a Castilla gracias a Villamediana y Salinas. A Sá de Miranda y Camões, señalados por Rosales, yo añadiría la poesía de Diogo Bernardes, cuya poesía amatoria se publicó en 1597 con el título de Rimas varias. Flores do Lima. Ambos Villamediana y Salinas conocían muy bien la poesía de Bernardes, o por la edición impresa de 1597 o tal vez vía copias manuscritas de sus poemas.

El interés de Villamediana en la poesía portuguesa de finales del siglo XVI es un tema que hace falta explorar detenidamente, puesto que, aparte de los trabajos de Rosales, no tengo noticias de que otros críticos hayan estudiado realmente este aspecto de su obra. Aunque nació en Lisboa, en 1582, no tuvo otras conexiones con Portugal, pues volvió a Castilla siendo un bebé aún ${ }^{2}$, y sin embargo las semejanzas de tono entre su poesía y la de Camões son, como observó Rosales, tan fuertes que a veces es difícil distinguir entre los dos. El interés de Salinas en la poesía portuguesa requiere menos explicación. Era medio portugués vía línea paterna (su padre era Ruy Gómez de Silva, príncipe de Éboli) y sabemos que leía y escribía el portugués con soltura. También habría necesitado saber hablarlo bien, ya que cuando llegó a Lisboa a principios de abril de 1617 a tomar posesión de los cargos de virrey y capitán general, se esperaba de él que dirigiese los negocios diarios en la lengua del país, algo que por sus cartas sabemos que hizo ${ }^{3}$.

Además del castellano y el portugués, sabemos del contenido de su biblioteca que sabía leer también el italiano, el francés y el latín, si bien echaba mano de vez en cuando de alguno de sus diccionarios bilingües. El

1 Una versión más amplia de este artículo se encuentra en Rosales (1972).

2 Su padre, Juan de Tassis y Acuña, I conde de Villamediana, era Correo Mayor del Reino y como tal acompañó a Felipe II a Portugal cuando este fue allí a tomar posesión de la corona en 1581. Un año más tarde nació su hijo y futuro II conde de Villamediana.

3 Formaba parte de los Acuerdos de Thomar que la administración de Portugal siguiese en manos portuguesas y que todo se llevase en portugués. Sobre las cartas que Salinas dictaba y también escribía en portugués, ver la Introducción de Dadson [en prensa]. 
ser bilingüe en castellano y portugués debería haber sido ventajoso para él, en particular visto que su carrera política coincidió más bien con el período en que Portugal formaba parte de la Monarquía Hispánica, pero como demuestra la cita que encabeza este artículo, esto no era necesariamente así: "Yo no puedo salir del trabajo de parecer a los portugueses castellano y a los castellanos portugués», escribió a Felipe III el 7 de abril de 1618, un año justo después de haber asumido el virreinato ${ }^{4}$. Los castellanos locales no se fiaban de él porque lo veían como portugués y como virrey que favorecía a los portugueses (lo que era en parte verdad), y los portugueses desconfiaban de él porque lo consideraban un castellano odiado puesto en Lisboa para gobernarles (que también era verdad).

Pero lo que era un obstáculo en términos políticos, en términos literarios era claramente un beneficio, ya que Salinas era uno de los pocos poetas castellanos de su época que podía interactuar, y de hecho interactuaba, con la poesía que se escribía entonces en portugués. Me parece que hay al menos cuatro modos de averiguar lo que un poeta podía haber sabido de la obra de otros poetas: 1) la evidencia de sus propios textos, donde encontraremos referencias directas e indirectas, citas intertextuales que nos llevarán a otro poeta antiguo (es decir, clásico) o moderno; 2) la evidencia de sus lecturas mediante un estudio y análisis de los libros que poseía y que por esto probablemente leía; 3) la evidencia proveniente de otros documentos, como cartas, memorias, diarios, donde se refiere a estas lecturas; y 4) la evidencia de copias hechas de los poemas de otros y, a veces, las anotaciones que las acompaña.

$\mathrm{Ni}$ que decir tiene que el poder utilizar estas cuatro categorías con un solo poeta es muy difícil y poco habitual. La primera categoría es bastante fácil, ya que solo hace falta estudiar los textos poéticos y saber reconocer las voces y ecos de otros poetas que pueblan las sombras del palimpsesto. La segunda, por extraño que parezca, es bastante más complicada y rara, por el hecho de que tengamos tan pocos inventarios hallados y publicados de los libros de poetas españoles áureos, especialmente el caso de los escritores más famosos. No sabemos nada o casi nada de los libros que poseían Garcilaso, Cervantes ${ }^{5}$, Lope de Vega, Góngora, Calderón, Tirso de Molina, y muchos más. De muchos de los principales poetas del siglo XVI

4 Dadson [en prensa], carta 82.

5 Aunque no se ha encontrado todavía la biblioteca de Cervantes, Daniel Eisenberg ha intentado reconstruirla en sendos trabajos: 1986 y 1987. 
- Garcilaso, Cetina, Acuña, Aldana, Camões - no tenemos información de sus lecturas mediante los libros de su biblioteca; solo se han publicado noticias sobre la librería de Luis Barahona de Soto y un estudio de las lecturas de Fernando de Herrera ${ }^{6}$. De los del XVII tenemos varios trabajos sobre la biblioteca de Diego de Silva y Mendoza, conde de Salinas ${ }^{7}$, un estudio de los libros del conde de Rebolledo, autor de los Ocios $(1650)^{8}$, y algunas noticias sueltas de la gran biblioteca de Francisco de Quevedo ${ }^{9}$, y poco más.

La tercera categoría tampoco ofrece muchas esperanzas para esta época: se han trabajado y publicado muy pocos epistolarios de escritores, y diarios y memorias destacan por su ausencia. En cuanto a la última categoría - copias de poemas hechas por un poeta, lo que demostraría sus intereses y gustos poéticos-, esto supone la existencia en algún lugar de un archivo privado que haya sobrevivido varios siglos y todas las vicisitudes del tiempo.

Al llegar a este punto, el panorama parece desde luego poco halagüeño para poder investigar las lecturas poéticas de los poetas españoles del Siglo de Oro. Sin embargo, hay un caso, casi milagroso, que cumple con las cuatro categorías o condiciones que acabo de exponer, y es el de Diego de Silva y Mendoza, y esto nos permite examinar en bastante detalle lo que sabía y leía de la poesía portuguesa a principios del siglo XVII.

Empecemos con su biblioteca: tenía un ejemplar de Camões, casi seguramente las Rhythmas de 1595, y otro de Francisco Rodrigues Lobo, As Églogas (Lisboa: Pedro Craesbeeck, 1605) ${ }^{10}$. No aparece ningún otro poeta portugués, aunque poseía muchos libros en portugués de escritores portugueses, en especial sobre temas políticos y religiosos. Bastantes

6 Rodríguez Marín, 1903: 520-551; Ruiz Pérez y Rojas Pérez (1997).

7 Dadson (1994-95). Hay una versión revisada y aumentada en Dadson, 1998: $205-$ 214 y 391-409. Últimamente, Dadson ha publicado un nuevo inventario de los libros del conde de Salinas (2016).

8 Casado Lobato (1973).

9 El primer estudio detallado de los libros de Quevedo (Maldonado, 1975) solamente trata de una parte de la enorme biblioteca que sabemos que poseía Quevedo. Este trabajo pionero ha sido revisado y ampliado por Fernández González y Simoes (2011 y 2012) y Pérez Cuenca (2015). Sobre los libros que anotaba, ver Schwartz (1998); Schwartz y Pérez Cuenca (1999); Pérez Cuenca (2003); y Alonso Veloso (2010a y 2010b).

10 Ver Dadson, 1998: 394, número 23, y 396, número 46. Para más libros de Salinas, entre ellos unos cuantos en portugués, ver Dadson (2016). 
de ellos fueron dedicados a él como nuevo virrey y, por tanto, posible mecenas $^{11}$.

Las únicas citas intertextuales que he encontrado en sus poemas son citas indirectas de Camões y Diogo Bernardes; es decir, que no reconocen su procedencia. Uno de los poemas más populares de Salinas y, por tanto, más copiados, es su glosa «En la fuente está Leonor» (Silva y Mendoza, 1985: 162-163, poema LXXXVIII), basada sin duda en una glosa parecida de Camões: «Na fonte está Leonor» (Camões, 1962: 137-138). Una relación más directa viene en la glosa que Salinas compuso sobre el pie «También para los tristes hubo muerte» (Silva y Mendoza, 2016: 95, poema 64); es el último verso de la Écloga I de Camões «À morte de D. António de Noronha, que morreu em África, e à morte de D. João, príncipe de Portugal, pai del-Rei D. Sebastião»:

La lumbre de tus ojos tan hermosos

yo la veré muy presto; y podré verte, que, a pesar de los Hados enojosos, también para los tristes hubo muerte. (Camões 1985: 20)

Villamediana también glosó este verso en sendas octavas reales. Puesto que ambos condes emplean las mismas rimas asonantes en sus respectivas octavas, es probable que el pie a glosar formara parte del certamen de una academia literaria.

Un soneto que viene atribuido a Salinas en todos los manuscritos más fiables es «Es el gozado bien en agua escrito» (el número 23 en todos ellos). Rosales estaba convencido de que era la traducción de un original portugués «É o gozado bem em agoa escrito», atribuido a menudo a Camões (aunque solamente aparece en la edición de 1668 de su obra y ha sido excluido del canon de su obra por los críticos de más peso) ${ }^{12}$. No obstante, es posible que Salinas creyera que era de Camões y que le gustara tanto que lo quisiera pasar al castellano, o, como sostiene Jorge Manrique Martínez, «que fue el Conde de Salinas - como en otras ocasiones- que se tradujo a sí mismo al portugués» (1993: 618).

11 Ver Dadson (2019).

12 Ver Leodegário A. de Azevedo Filho, 1985: 216; «Autoria camoniana contestada». 
Hay tantas posibles referencias a Camões en la poesía de Salinas que sería enojoso enumerarlas todas, pero las siguientes serán suficientes para dar una idea de su deuda poética al poeta más grande de Portugal.

Los versos de los cuartetos del soneto XII («Quereros para mí no es desamarme») terminan todos en infinitivo más «me»: desamarme / quererme / aborrecerme / amarme; ayudarme / vencerme / defenderme / quitarme (Silva y Mendoza, 1985: 48). Es posible que Salinas tuviera en mente una fórmula parecida empleada por Camões en su soneto 38 («Dai-me uma lei, Senhora, de querer-vos»): querer-vos / enojar-vos / amar-vos / obedecer-vos, etc., donde una de las rimas es «aborrecer-vos» ${ }^{13}$. También puede que fuera influido por el soneto 23 de Diogo Bernardes ( «Se poder tanto á morte defender-se»), donde cada rima de los cuartetos es infinitivo más reflexivo «se»: defender-se / estimar-se / apagar-se / escurecer-se; converter-se / descorar-se / mudar-se / ver-se (Bernardes, 1945: 23).

El verso «me parece cada hora cien mil años / y que en ellos no puedo hallar una hora» (Silva y Mendoza, 1985: 39, soneto III) procede directamente del soneto 22 de Camões («Tanto de meu estado me acho incerto»): «Numa hora acho mil anos, e é de jeito / que em mil anos não posso achar uma hora» (Camões, 1962: 198-199) ${ }^{14}$.

En cuanto a Diogo Bernardes, una de las glosas más célebres de Salinas es «Espero, y sé que me engaño / mas no sé desconfiar» (Silva y Mendoza, 1985: 187-188, poema CXII). Una variante de esta copla fue empleada dos veces por Bernardes: «S'espero sei que m'engano / mas não sei desesperar» (Bernardes 1945: 201-202 y 213). Es muy posible que la copla de Bernardes fuese la original que Salinas copió. Otra glosa de Salinas tomó como pie la siguiente copla:

\author{
¿De qué sirve, cruel amor, \\ hacer de dos almas una, \\ si las aparta Fortuna? (Silva y Mendoza, 2016: 114, poema 87)
}

Bernardes glosó la misma copla: «De que sirve, ó crudo Amor, / hazer de dos almas una, / si las aparta fortuna?» (Bernardes 1945: 227-228). En

13 Según Azevedo Filho, es «atribuição camoniana incontroversa» (1985: 89)

14 Otro soneto de «autoria camoniana incontroversa», según Azevedo Filho (1985: 94). Cf. también 2 Pedro, 3:8: «Pero, amados, no ignoréis que, para el Señor, un día es como mil años y mil años como un día». 
este caso, sin embargo, leemos que la copla es «alheia», es decir ajena, no de Bernardes sino de otro.

Otra copla glosada por Salinas y un poeta portugués, esta vez Fernão Correa de Lacerda, es «No es menester que digáis / cuyas sois, mis alegrías, / que bien se ve que sois mías / en lo poco que duráis» (Silva y Mendoza, 1985: 196-197, poema CXXII). Versiones de la glosa de Correa de Lacerda aparecen en el Cancioneiro de Corte e de Magnates (finales del siglo XVI-principios del XVII) y en el Cancionero Mendes de Britto (de hacia 1623) ${ }^{15}$. Visto que hay otra glosa de esta copla en Mendes Britto, esta vez anónima, es muy probable que fuese tema de una academia literaria.

Puede que Salinas conociera la poesía de Diogo Bernardes, y otros poetas portugueses, mediante otro camino, y ese fue la poesía del conde de Villamediana. Como escribí en un artículo de hace más de treinta años, Villamediana y Salinas tomaron parte en un tipo de diálogo subtextual en sus versos, donde cada uno respondía al otro y sus versos en una suerte de juego intertextual de a ver quién reconoce la referencia ${ }^{16}$. A veces uno contestaba directamente al verso del otro, o lo contradecía o lo parodiaba. Pero había también una tercera persona en este juego: Diogo Bernardes, ya que muchos de sus versos son la base de los de Villamediana que luego Salinas imitaba, parafraseaba o comentaba. Esta relación triangular precisa de más investigación.

Un ejemplo excelente de la interacción entre poetas castellanos y portugueses es el soneto que empieza «Perdime dentro em mim como em deserto» de Martim de Castro do Rio. Villamediana lo pasó al castellano y Salinas cogió el primer verso, ligeramente cambiado, para dar remate a unas octavas «Tardanzas, confusión, contradicciones»: «Piérdome dentro en mí como en desierto» (Silva y Mendoza, 1985: 108, poema LXV, v. 24) ${ }^{17}$. También empleó el verso en su mote de Palacio: «Soledades de antecámara» (Silva y Mendoza, 2016: poema 131), donde uno de los participantes, Beltenebros, dice "piérdome dentro en mí como en desierto», mientras que el otro, Don Florestán, contesta «piérdome dentro en mí como en poblado». En el Cancionero Mendes de Britto y BNE MS 4127

15 Para estos dos cancioneros, ver, respectivamente, Askins (1968) y Rozas (1965).

16 Dadson (1993).

17 Para más sobre este soneto muy conocido en la época, ver Carreira, 1990: 113. Askins (1968: 573-574) atribuye el original portugués a Martim de Castro do Rio y discute otras versiones portuguesas y castellanas del poema. 
se atribuye otro soneto con este verso a Francisco de la Cueva. Rosales ha sugerido que de la Cueva glosaba el verso de Salinas, quien a su vez lo había tomado del poema portugués original ${ }^{18}$.

Parecido ejemplo es el soneto «Nunca en amor dañó el atrevimiento», atribuido a Villamediana en un manuscrito de su obra en la Biblioteca Menéndez Pelayo ${ }^{19}$, aunque Blecua señaló una atribución a Bartolomé Leonardo de Argensola mientras que Mendes Britto (fol. 7v) lo atribuyó al conde de Vimioso $^{20}$. Rosales creía que era copia directa o traducción de «Nunca em Amor danou o atrevimento» de Camões, pero la autoría de Camões de este soneto es muy dudosa (apareció por primera vez en la edición de Alvares da Cunha de 1668) y ha sido rechazada por Azevedo Filho $^{21}$. No obstante, es más que probable que circulase en la época como de Camões y de ahí que atrajese la atención de Villamediana. Un último giro lo proporciona Edward Glaser, que escribió lo siguiente en referencia a este soneto: "The reader's bewilderment increases when he discovers that Faria e Sousa claimed for the canon of Camões Nunca em amor danou o atrevimento. This poem is obviously the Portuguese version of a Spanish original which the consensus of seventeenth-century anthologists ascribed to the Count of Salinas» (1966: 225). Desgraciadamente, no nos dijo dónde se encontraba este «consenso» ni quiénes eran estos antologistas del siglo XVII. Claude Gaillard (1988) no lo incluyó en su inventario exhaustivo de los poemas de Salinas, y yo no he encontrado ni un manuscrito donde se adjudique a Salinas.

Otro ejemplo de la relación triangular entre los dos condes españoles y Camões es el verso 2 del soneto XXVI de Salinas «haces del bien pasado mal presente» (Silva y Mendoza, 1985: 62). Hallamos una versión de él en el soneto "Cansado de mí mismo, y más cansado» de Villamediana: «Si el bien pasado es siempre mal presente» (Rozas, 1965: 73). Su origen parece encontrarse en Camões: «Soubera-me lograr do bem passado, / se conhecer soubera o mal presente» («Doces lembranças da passada glória»;

19 MS 99, «Poesías del Conde de Villamediana», fol. 154r (Artigas y Sánchez Reyes, 1957: 203).

20 Ver Argensola, 1974: II, 272 (atribución de BNE MS 18.405, fol. 55), y Rozas, 1965: 14

21 Dice tajantemente: «Sem qualquer prova aceitável de autoria camoniana» (1985: 137). 
Camões, 1962: 213, soneto 47), que evidentemente debe mucho al soneto $\mathrm{X}$ de Garcilaso « $\mathrm{iOh}$ dulces prendas por mi mal halladas». Aquí vemos en su totalidad la línea de sensibilidad garcilasiana descrita por Rosales.

Otros contactos entre Salinas y los círculos literarios portugueses se hallan en algunos de sus Motes de Palacio, en un Torneo de 1608, y en un Vejamen de hacia 1612. Un Mote de Palacio anónimo procedente del Cancioneiro de Corte e de Magnates hace poco que atribuí a Salinas puesto que trata de varios miembros del Consejo de Portugal de principios del siglo XVII además de algunas damas de la corte que aparecen con bastante frecuencia en los motes que sabemos que son suyos ${ }^{22}$. Naturalmente, como resultado de la anexión de Portugal a la Monarquía Hispánica en 1580, había bastantes nobles portugueses con sus mujeres e hijas residentes en la corte de Madrid a principios del siglo XVII, y muchos de ellos tomaron parte en los Motes de Palacio que Salinas escribió como parte de las diversiones palaciegas: Gonzalo Coutiño, Maria Coutiño, Francisca de Távora y sus hermanas, Beatriz de Villena (hija de Henrique de Sousa, gobernador de Oporto), Leonor de Melo, y otros. De vez en cuando, Salinas pone en boca de una de las damas portuguesas una respuesta en portugués, como en el Mote «Perpetuo aborrecimiento»: «Ni aun para isso não há memória» (Doña Paula Margarida de Castro) (Silva y Mendoza, 2016: 144).

Entre los papeles privados de Salinas encontramos una pieza curiosa titulada «Torneo en Lisboa, de los ministros y fidalgos, 1608» ${ }^{23}$. Describe varias «quadrilhas» y la «emprêsa» que cada noble llevaba con su letra, como en los ejemplos siguientes:

Dom António Pereira trazia para emprêsa Argos; em lugar de olhos trazia línguas pintadas, e a letra dizia assim:

Todas vão por um compasso;

todas seguem uma derrota;

todas falam tracanhota, mais deprêsa ou mais despaço.

O Marquês de Castelo Rodrigo levava para emprêsa Dédalo, e dizia a letra assim:

22 Silva y Mendoza, 2016: 307-309, poema 172.

23 AHN, Nobleza, Osuna, CT. 543-311. 
Não quis subir ao mais alto, porque o meio é mais siguro.

Son tão claro como escuro quem su redada Amor salto.

Dom Gonzalo Coutinho vinha em figura de Floriano do Deserto e trazia para [emprêsa] muitas damas pintadas num escudo, com cada uma figa dada, e a letra dizia assim:
Tantas damas namorei, e lhe dei tantas fadigas, que me deram muitas figas e com isso me fiquei.

El resto de las empresas y letras son igualmente oscuros, pero es de suponer que significaban algo para los participantes del torneo. Entre los que tomaron parte estaban: o Conde de Sabugal, Francisco de Castelo Branco, Juan de Castelo Branco, Gonçalvo Pires de Carvalho, Diogo de Castelo o Branco e o Preto, o Capelão Mor, Martim Gonsalves, Carlos de Noronha, Francisco Rolim, António de Ataíde, Francisco Correa, o Conde de Atouguia, o Conde de Monsalvo, Fernando de Alvares de Castro, y Pedro de Mendoça. Lo que no está claro es el por qué esta pieza aparece entre los papeles privados de Salinas. ¿La escribió él? ¿La hizo copiar a causa de los participantes (todos nobles portugueses de la primera década del XVII)? La letra es una que he visto otras veces en sus papeles, de ahí que sea probablemente la de uno de sus secretarios «da língua portuguesa». Es imposible ahora determinarlo, pero proporciona desde luego un vistazo interesante del mundo de la corte hispano-portuguesa en el que se movía.

$\mathrm{Y}$ esto es igualmente evidente en el vejamen de academia que encontramos en dos manuscritos portugueses (ambos en Évora) y uno castellano (en la BNE): «Vejamen literario sobre un terremoto que amenazó de muerte a los miembros del Consejo de Portugal» (h. ¿1612?) ${ }^{24}$. La versión

24 Biblioteca Pública de Évora [BPE], Códice CXII/1-40, fols. 134r-147r; BPE, Códice CXIV/2-9, fols. 201r-202v (versión algo defectuosa e incompleta); BNE MS 9087, fols. 143r-150v. Aunque ninguna de las versiones lleva fecha, se puede avanzar la fecha de 1612 con bastante confianza. A principios de ese año Cristóbal de Moura volvió a Madrid desde Lisboa, dejando el gobierno de Portugal en manos de don Pedro de Castilho, obispo de Leiria. Una vez en la capital Moura participó en una junta que se reunía en casa 
en castellano es claramente una traducción más bien pobre del original en portugués, pero proporciona una semblanza muy simpática y curiosa del conde que, curiosamente, no se encuentra en las versiones portuguesas:

Llevábale un paje un espejo delante, para en él, sin doblarse ni descomponerse, ver el aire y meneo con que andaba y ponía los pies, y también porque en casa no tuvo lugar para acabarse de afeitar, cuando se encontró con los demás cortesanos que venían de las Cortes, y quedó muy pesaroso de no haberse hallado en ellas, para proponer cierta cosa que traía estudiada; y daba por razón de su tardanza, que se detuvo en buscar un consonante para aprovecharse de un concepto suyo de que quería componer un romance que estaba haciendo, excusándose también con lo mucho que madrugan los de las Cortes, porque en aquel instante había contado las doce en el reloj de Palacio. Fuéronse llegando a él muchos hidalgos y pretendientes portugueses, que le acompañaban, a cada uno de los cuales él recibía con afabilidad, y con rostro muy alegre, usando con ellos de grandes cumplimientos y palabras en portugués, en voz muy flemática. (Rosales, 1974: 531) 25 $^{25}$

O sea, era simpático y afable, hablaba el portugués «en voz muy flemática», y llegaba tarde a las citas por su obsesión con la poesía y porque, al parecer, no le gustaba madrugar ${ }^{26}$.

del confesor real, fray Luis de Aliaga, y que tenía el cometido de reformar el Consejo de Portugal (objeto de las burlas de la pieza). Pedro Cardim (siguiendo a Danvila y Burguero [1900: 828]) considera este vejamen como uno de «varios papeles que entonces circulaban por Madrid y que tenían precisamente como objeto esas intenciones reformadoras de Felipe III y su valido» (2017: 180). Entre los miembros del Consejo mencionados en el vejamen encontramos a Moura y «o Bispo Vizorrei» (que ha de ser Pedro de Castilho). Como Moura murió el 27 de diciembre de 1613 (Martínez Hernández, 2011: 96), la pieza no puede ser posterior; en efecto, todo indica que se refiere al año anterior, a los intentos de reforma del Consejo y a la suspensión del mismo (tal vez el significado del título de «terremoto»).

25 En su acotación al poema, Rosales dijo, muy acertadamente, que «Copio textualmente el manuscrito. Las irregularidades métricas y de rima se deben indudablemente a que los versos del epitafio se encuentran traducidos improvisadamente del portugués» (1974: 532). Él no había visto el original en portugués, ni sabía, parece ser, que existía.

26 La verdad es que, por mucho que le gustara quedarse en la cama hasta tarde, sus ocupaciones políticas raramente le daban esta posibilidad. La evidencia de sus propias cartas demuestra que se acostaba muchas veces muy tarde (pasadas las doce de la noche) y que se levantaba muy temprano, una vez para asistir a una reunión en Lisboa que empezó a las seis de la madrugada. 
El humor del vejamen propio reside en la idea de que todos los miembros del Consejo de Portugal están tan aterrorizados por el terremoto «que com o medo e perigo fizeram os mais deles testamento». Como observa el autor: «houve ministros que se viram nas mãos dos diabos, e poucos que se quiseram pôr nas mãos de Deus». La parte que se refiere a Salinas dice:

El conde de Salinas: O conde de Salinas estava fazendo umas redondilhas quando se levantou a tormenta e não achava consonantes ou [es]drújulas para elas. Voou-lhe o papel e tinteiro e ficou com a pena na mão, desacordado do sobresalto, e, parescendo-lhe que morria, disse: «Pésame que pierden los portugueses uno que siempre lo ha sido en su favor, en tiempo que todos son contrarios unos para otros». Fez testamento muito honrado e deixou the escrevessem na sepultura:

Aqui yaz um castelhano de portugués enxertado, que só soube ser honrado sem fazer a ninguém dano.

A nenhum homem fez mal quando não fizesse bem, nem se queixa dele alguém de Castela ou Portugal.

Foi prolixo em o dizer, mas discreto todavia, e pede uma Avemaria a quem lha quiser dizer.

En realidad, Salinas no sale demasiado mal de esta pieza burlesca, y desde luego bastante mejor que los demás miembros del Consejo de Portugal, de los que todos por supuesto eran portugueses. Observamos que «só soube ser honrado / sem fazer a ninguém dano», y «A nenhum homem fez mal / quando não fizesse bem», y que él mismo señala que siempre intentaba favorecer a los portugueses (algo que sus cartas enviadas desde Lisboa demuestran ser verdad) ${ }^{27}$. También es curioso y bonito el retrato que hacen de él interrumpido en la composición de unas redondillas. Es decir, primero se pone el énfasis en el poeta y después en el político, el virrey.

27 Ver Dadson [en prensa]. 
En una composición larga y muy curiosa, mezcla de prosa y verso, titulada «Respuesta de los catarriberas enviada por el Bachiller de Arcadia contra el Comentador y comento de los Motes» (Silva y Mendoza, 2016: poema 134), y que resulta ser un comentario burlesco por Salinas de su propio Mote de Palacio «Son pensamientos dolientes», encontramos la siguiente referencia al Cancioneiro Geral de Garcia de Resende (empezado en 1483 pero no impreso hasta 1516): «Si no sabe lo que dio que decir a las coplas el hablar latín a las damas, pregúntelo al Cancionero Viejo de Portugal, donde verá las que llovieron sobre un galán latino siendo el estribillo que tomaron:

Oh, desditado de tim, homem mofino, que vieste a nascer em sino de latim.»

Según el profesor Hélio Alves, de la Universidad de Évora, que muy amablemente contestó a mis preguntas, el verso «em sino de latim» sí que aparece en el Cancioneiro de Resende, en algunos versos que D. Francisco de Portugal, I conde de Vimioso, envió a Alves Teles.

En la misma composición Salinas cita algunos versos de otro poema portugués, que no hemos podido identificar:
A calidade deste fruto
hei de homens que já vim
que prometem de sim muito
e dão muy pouco de sim.

Entre sus propias composiciones encontramos una glosa sobre la copla

Marta, desse teu rostrinho

minha vista não se farta,

que, picando como espinho,

é brando como de marta

e branco como de arminho.

(Silva y Mendoza, 2016: poema 52) 
La glosa está en castellano, pero cada estrofa termina con el verso relevante en portugués, demostrando así las habilidades lingüísticas del poeta. Se trata sin duda de un poema escrito por Salinas cuando vivía en Lisboa, con toda certeza hacia el año de 1620. Otra glosa en portugués de probable autoría saliniana es la siguiente:

Passou o meu dano;

eu lhe disse: he!

Fez que não ouvia,

não sei que isto é. (Silva y Mendoza, 2016: poema 165)

La única copia que tenemos de este poema se encuentra en el Arquivo Nacional Torre do Tombo [ANTT] MS 1737, fol. 88r, pero aparece justo al lado del poema anterior, «Marta, desse teu rostrinho», que ahora sabemos que es de Salinas puesto que tenemos una versión autógrafa de él además de la de ANTT MS 1737. Hasta el descubrimiento de la versión autógrafa, se tenía por muy dudosa la atribución de esta glosa a Salinas. De hecho, ni aparecía en el inventario de sus versos hecho por Gaillard. Y esto me lleva a la última parte de este trabajo, que concierne la circulación de algunos de los poemas de Salinas en Portugal, y lo que esto significa para una edición crítica de su obra poética.

De los siete principales cancioneros manuscritos de la poesía de Salinas, dos se encuentran en Portugal: ANTT MS 1737 y Biblioteca Geral da Universidade de Coimbra [BGUC] MS 316. Este último manuscrito, copiado por un escriba portugués, se terminó de hacer el 30 de enero de 1652, como nos dice el copista al final del bloque de poemas de Salinas: «Fim das obras do Marquez de Alanquer excellentissimo poeta, e discreto em reportas, e dittos auizados. Oje 30 de janeiro de 1652 anos». Estos tenían originalmente su propia foliación, que iba de 1 a 79 (moderna 51 a 129), y por tanto formaban un cartapacio aparte. No tenemos por qué no creer que esta copia en particular se hiciese entonces, si bien la original en la que se basaba se confeccionase muchos años antes. ANTT 1737 no tiene fecha, pero la sección que contiene los poemas de Salinas (de nuevo un grupo propio que va del folio $85 \mathrm{r}$ al $115 \mathrm{v}$, con el título de «Obras do Marques de Alenquer») fue recopilada probablemente en la década de 1620.

Ambos manuscritos contienen poemas que no se encuentran en los principales cancioneros castellanos, de ahí que habitualmente se hayan tratado con suma cautela en cuanto a su autoría. Sin embargo, mi hallazgo de un 
gran número de originales de Salinas demostró que hay que tomar con mucha más seriedad estos dos manuscritos portugueses, en particular ANTT 1737, ya que es posible que su copista tuviese acceso a originales del poeta. Por ejemplo, su versión de «Marta, desse teu rostrinho» tiene dos estrofas que Salinas rechazó más tarde a favor de dos nuevas ${ }^{28}$. ANTT 1737, por tanto, representa una versión más temprana del poema, versión que su copista había sin duda visto. El cómo, es una muy buena pregunta, puesto que, en lo que sabemos, estos originales no salieron nunca de la Casa de Salinas, quedando durante siglos entre los papeles privados de la familia. Esto sugiere que el copista de ANTT 1737 fue en algún momento miembro de la Casa del poeta, tal vez un secretario portugués con acceso a los papeles del virrey. Otra posibilidad, por supuesto, es que una temprana versión del poema circulase en Portugal, entre tal vez amigos y conocidos de Salinas, y fue esta la que llegó a manos del copista de ANTT 1737. Más tarde, de vuelta a Madrid, cuando Salinas se puso a recoger sus poemas sueltos, ayudado por su hijo Rodrigo y su secretario de muchos años Domingo de Sagastiberria, decidió cambiar dos estrofas del poema escribiendo dos nuevas. Esta es la versión que publicamos en 2016.

En mis esfuerzos por localizar poemas de Salinas y establecer un canon fiable de su obra, se ha hecho evidente que un número considerable de ellos solo circulaban en Portugal. No se encuentran por tanto en las cinco principales colecciones castellanas, que pueden fecharse todas a antes de 1621-1622, cuando Salinas abandonó Lisboa para volver a Madrid. El último de estos manuscritos en ser recopilado, Hispanic Society of America [HSA] MS B2460, tiene poemas que datan de 1622 (por ejemplo, un soneto retrato escrito para su futura nuera la duquesa de Híjar), pero ninguno procedente de años posteriores ${ }^{29}$. Entre los originales y copias que encontré y que publiqué en 2016 con el título de Obra completa. I. Poesías desconocidas, hay poemas que se escribieron mientras Salinas estaba en Lisboa y luego en Madrid; algunos se pueden fechar para mediados y fines de la década de 1620, incluso hasta un año antes de su muerte ${ }^{30}$. Pero también es posible que haya otros poemas suyos de estos años (y también de antes) que solamente se encuentran en manuscritos portugueses.

28 Ver la discusión de esto en Silva y Mendoza, 2016: 81-85.

29 Sobre estos manuscritos y sus probables fechas de composición, ver Dadson (2008).

30 Ver el Índice VI de Silva y Mendoza (2016) para las fechas de algunos de estos poemas. 
Un buen ejemplo de esto es el célebre Cancionero Mendes de Britto 1623 (BNE MS 17.719). Muy conocido por el gran número de poemas de Villamediana que tiene (muchos de los que no se encuentran en ningún otro manuscrito), copia también un buen número de poemas atribuidos a Salinas. Algunos de estos son muy conocidos por aparecer en otros manuscritos, y por tanto no representan ningún problema editorial, pero otros, en especial algunos sonetos, solamente se encuentran en el Cancionero Mendes de Britto. En cualquier edición de la obra poética de Salinas estos poemas se clasificarían bajo el marbete de autoría dudosa, y serían excluidos. Y sin embargo es bien posible que algunos sean de verdad de Salinas. Heitor Mendes de Britto, el supuesto recopilador del manuscrito, era persona muy conocida de Salinas. Como uno de los negociantes y empresarios más ricos de Lisboa y cabeza de una familia numerosa y extendida de financieros conversos, su apodo de Heitor Mendes de Britto o Rico era bien merecido. Salinas trataba casi a diario con él, pues Mendes de Britto y sus socios financiaban en gran parte la monarquía portuguesa durante las primeras décadas del siglo XVII, además de proveer al propio Salinas con préstamos sustanciosos. Sus cargos de virrey y capitán general no eran remunerados y como Alastair Malcolm ha observado reciente e irónicamente: «[s]election for ambassadorial and viceregal posts might bring reputation and experience, but could seriously undermine a nobleman's wealth $»^{31}$. Es más que probable que Salinas supiera que Mendes de Britto estaba formando un cancionero de poemas que le gustaban, y que le pasara algunos de los suyos. Si el recopilador de este manuscrito y el financiero converso eran la misma persona, y todos los que han estudiado el manuscrito parecer pensar que lo son, entonces ¿qué razón tendría Mendes de Britto en adjudicar a Salinas poemas de otro, especialmente cuando los dos hombres se conocían tan bien?

Lo mismo se puede decir, aunque en grado menor, de otros poemas de Salinas que solamente se encuentran en manuscritos portugueses. Salinas no era ni mucho menos un Lope, un Góngora o un Quevedo, a quienes se han atribuido erróneamente numerosos poemas que no son suyos. Es verdad que en Portugal era relativamente bien conocido como un virrey que escribía poemas: «Um Viso-Rei que faz trovas», como decían, pero ¿es esa

31 Malcolm 2017: 132. El humor viene del juego de palabras entre «wealth» [riqueza] $\mathrm{y}$ «health» [salud]. En los paquetes de cigarrillos vendidos en Inglaterra se encuentra el aviso: «El fumar puede dañar seriamente su salud». Aquí Malcolm dice que los puestos de embajador o virrey pueden hacer lo mismo. 
suficiente razón para poner su nombre a un buen número de sonetos de otra manera anónimos? Para tomar solamente un ejemplo: el soneto «Si mil vidas tuviera que entregaros» se encuentra en al menos 21 manuscritos, la mayoría en Portugal, y dos impresos ${ }^{32}$. En siete de los manuscritos se atribuye directamente a Salinas, en dos se encuentra dentro de un grupo de poemas de incontestada autoría saliniana, en diez viene sin atribución, y en los demás se atribuye a Lope de Vega, a Bacelar, y dos veces a un tal Sertorio. Askins cree dudosa la atribución a Lope, muy dudosa la atribución a Bacelar («an obvious error», dice), pero no dice nada de «Sertorio». En ediciones muy tardías (y de poca confianza) de Camões también se le atribuye a él. Curiosamente, en el Códice 173, Fondo Manizola, de la Biblioteca Pública de Évora, manuscrito formado en su casi totalidad de sonetos anónimos, este es el único que lleva una atribución: «Del conde de Salinas a una dama $\rangle^{33}$. Gaillard dice lo siguiente del soneto:

Este soneto, ausente de las colecciones fidedignas pero atribuido en tres cancioneros portugueses, posiblemente haya sido compuesto, o mejor dicho reelaborado de memoria por Alenquer, a partir de otra composición que circulaba en España antes de 1605. En efecto, tiene evidentes analogías con el soneto «Si mil almas tuviera con que amaros» recogido por M. de Madrigal en la Segunda parte del Rom. Gen., f. 191 r-v, an. (1988: 56)

Sin embargo, Arthur Lee-Francis Askins, escribiendo sobre el poema antes que Gaillard, creía algo distinto:

on numerous occasions, especially in MSS of Portuguese provenience, [it] is ascribed directly to Diogo de Silva e Mendoça, the Conde de Salinas and Marquês de Alenquer, or copied in groups of other poems known to be his. It is very possible that the Conde de Salinas was indeed the author of the sonnet in its present form, as the weight of evidence would have it, by the reworking of materials from other sources. (1974: 174)

Carreira, que habla de un soneto «fecundo en transmutaciones», dice que la hipótesis de Gaillard — que el soneto de Salinas es una reelabo-

32 Hay una lista de estos en Askins, 1974: 174-175, que hace falta actualizar.

33 Askins no conocía la existencia de este manuscrito, por tanto, no figura en su lista (de la nota anterior). 
ración del que aparece en la Segunda parte del Romancero General de 1605- es discutible, y parece abogar por la tesis de Askins, de que la versión de Salinas es «la que está en el origen de otras siete conocidas» (1990: 70). A pesar de estos apoyos tan fuertes, el soneto nunca ha sido incluido en el canon de la obra poética de Salinas. Al menos debería figurar como de autoría posible.

El manuscrito 51-II-4 de la Biblioteca do Palácio de Ajuda, Lisboa, contiene un grupo de sonetos atribuidos todos a Salinas: «En mármol es el bien gozado» (fol. 6r), «Si en mármol es el bien gozado» (6r), «No está el gozado bien en el alma» (6v), «En vano se me oponen las montañas» (7r), «De aromáticos leños nido forma» $(7 \mathrm{v})$, «Soberbia voluntad desenfrenada» (7v), «¿De qué sirve encubrir mi pena» (8r). Aparte de uno de ellos — «En vano se me oponen las montañas»— los demás no se encuentran en ninguna otra compilación. Los tres primeros son claramente variantes de un soneto bien conocido de Salinas: «Es el gozado bien en agua escrito» (Silva y Mendoza, 1985: 59, soneto 23), y Jorge Manrique Martínez (1993: 616-618) ha defendido con mucha coherencia la autoría de Salinas para los tres $^{34}$. En cuanto a «De aromáticos leños nido forma», Antonio Carreira, que no toma a la ligera las atribuciones falsas, ha escrito: «Este soneto, desconocido por Gaillard, se atribuye al conde de Salinas en el ms. 51/II/4 de la Biblioteca da Ajuda, f. 7v, del s, XVII. Por el estilo, afín al de este poeta, bien podría ser éste uno de los textos que según el mismo crítico circularon casi exclusivamente en Portugal» (1990: 63). El único soneto del grupo que presenta problemas es «En vano se me oponen las montañas», que aparece anónimo en la Segunda parte del Romancero General (1605) de Miguel de Madrigal y como el soneto 4 de las Rimas (Zaragoza, 1634) de Lupercio Leonardo de Argensola ${ }^{35}$. Sin embargo, dado que Lupercio murió en Nápoles en marzo de 1613 y había pedido que se quemaran sus poemas a su muerte, el que este soneto apareciera en un volumen organizado por su hijo Gabriel Leonardo de Albión casi veinte años después de su muerte no es ninguna garantía de que fuera escrito por él. Puede que la atribución a Salinas sea la correcta.

El manuscrito A.T./L.285 (Archivo Tarouca, Biblioteca Nacional de Portugal) tiene muchos poemas de Salinas, pero solamente tres se atribuyen (eso sí, correctamente) a él. No obstante, las versiones de los demás

34 Ver también Carreira, 1990: 65, y Glaser, 1968: 206-207 (quien los publicó).

35 Ver Argensola, 1972: 51, poema 10. 
merecen tenerse en cuenta para una edición crítica de su obra, a pesar de la falta de atribución.

El problema que quiero destacar aquí es qué hacer con poemas con una única atribución. Nuestras prácticas editoriales habituales los excluirían de cualquier edición crítica: una única atribución, por fuerte que sea, es demasiado arriesgada. Con suerte tales poemas aparecerán en una lista de atribuciones dudosas, identificados solamente por el primer verso. Es por supuesto muy sensato pecar por exceso de precaución, pero puede significar que docenas y docenas de bellos poemas del Siglo de Oro español nunca son publicados o bien editados, de ahí que otro investigador más tarde no pueda comparar las versiones conocidas con una nueva, que tal vez ofrezca la atribución correcta. En el caso particular de Diogo de Silva e Mendonça, Marquês de Alenquer (como tan a menudo aparece en manuscritos portugueses) significa que el gran número de poemas suyos que probablemente circularon solamente en Portugal y que puede que representen composiciones de los últimos diez años, más o menos, de su vida, nunca se publicarán. José Ignacio Díez Fernández encontró el mismo problema con la edición de la poesía completa de Diego Hurtado de Mendoza (ilustre antepasado de nuestro Diego de Silva y Mendoza), explicando sus decisiones editoriales así:

En buena lógica, seguramente, y teniendo en cuenta la riqueza de la transmisión de esta poesía, habría que concluir que los poemas menos representados (¿con dos o menos copias? ¿con tres?) no son razonablemente de Mendoza, y creo que es así: razonablemente no son suyos, pero... ¿cuántas ediciones modernas de poetas de los Siglos de Oro rechazan un poema que sólo esté atestiguado una o dos veces? Las fuentes tienen todavía hoy un halo sagrado, aunque quizá no sea lo lógico ni lo razonable. Pero, no sólo hay que numerar y ponderar, pues no nos son conocidos todos los factores: ¿pueden algunos de los textos menos documentados proceder de academias, o de actividades cortesanas? ¿Pueden ser tardíos...? (Hurtado de Mendoza, 2007: LXXIX-LXXX)

Díez Fernández podría estar describiendo la situación de Diego de Silva y Mendoza, pues es más o menos la misma. Hemos listado casi 70 poemas atribuidos a Salinas, la mayoría con solo uno o dos testigos, y aunque bastantes se pueden excluir del canon de su obra por razones de peso - se encuentran, por ejemplo, en la obra impresa de otro poeta, o son 
demasiado tempranos para ser de Salinas - otros muchos bien podrían ser de su autoría. No olvidemos que unos cuantos de los poemas que publicamos en 2016 en la Obra completa. I. Poesía desconocida solo tienen un testigo: el cartapacio de poemas que Salinas y su secretario Sagastiberria, con la ayuda de su hijo Rodrigo, fueron formando y organizando durante los últimos años de su vida. El que sean originales autógrafos quita toda duda, pero si el mismo poema solo lo conociéramos por su inclusión en un manuscrito formado por un aficionado quedaría excluido de la edición de su obra. Así de delgada es la línea entre las atribuciones correctas y las falsas. Por tanto, en la edición que el Dr. Carreira y yo estamos preparando de su Obra completa. II. Poesía conocida seguiremos el excelente ejemplo dado por el profesor Díez Fernández, e incluiremos en un apéndice todos los poemas atribuidos a Diego de Silva y Mendoza, conde de Salinas y marqués de Alenquer. Seguramente, entre ellos habrá más de uno escrito de verdad por él.

\section{BIBLIOGRAFÍA}

Alonso Veloso, María José, «Quevedo en sus lecturas: anotaciones autógrafas y subrayados en cuatro impresos de la Biblioteca de Menéndez Pelayo», Manuscrt. Cao, 8, (2010a), pp. 1-48.

Alonso Veloso, María José, «Quevedo, lector del Anticlaudiano de Alain de Lille. Noticia sobre nuevas anotaciones autógrafas», La Perinola, 14, (2010b), pp. 277-303.

Argensola, Lupercio Leonardo de, Rimas, edición de José Manuel Blecua, Madrid, Espasa Calpe, 1972.

Argensola, Bartolomé Leonardo de, Rimas, edición de José Manuel Blecua, 2 vols, Madrid, Espasa Calpe, 1974.

Artigas, Miguel y Enrique Sánchez Reyes, Catálogos de la Biblioteca de Menéndez Pelayo. I. Manuscritos, Santander, Taller de Artes Gráficas de los hermanos Bedia, 1957.

Askins, Arthur L.-F. (ed.), Cancioneiro de Corte e de Magnates (MS. CXIV/2-2) da Biblioteca Pública e Arquivo Distrital de Évora, Berkeley, University of California Press, 1968.

Askins, Arthur L.-F. (ed.), The Hispano-Portuguese 'Cancioneiro' of the Hispanic Society of America, Chapel Hill, University of North Carolina, 1974. 
Azevedo Filho, Leodegário A. de, Lírica de Camões. I. História, metodologia, corpus, Lisboa, Imprensa Nacional-Casa da Moeda, 1985.

Bernardes, Diogo, Obras completas, com prefácio e notas do Prof. Marques Braga. Volume I: Rimas várias Flores do Lima, Lisboa, Livraria Sá da Costa, 1945.

Camões, Luís de, Obras completas, com prefácio e notas do Prof. Hernâni Cidade. Volume I: Redondilhas e Sonetos, Lisboa, Livraria Sá da Costa, 1962.

Camões, Luís de, Obras completas, com prefácio e notas do Prof. Hernâni Cidade. Volume II: Géneros líricos maiores, Lisboa, Livararia Sá da Costa, 1985.

Cardim, Pedro, Portugal y la Monarquía Hispánica (ca. 1550-ca. 1715), Madrid, Marcial Pons Historia, 2017.

Carreira, Antonio, «Nuevos textos y viejas atribuciones en la lírica áurea», Voz y Letra, 1, (1990), pp. 15-142.

Casado Lobato, María Concepción, «La biblioteca de un escritor del siglo XVII: Bernardino de Rebolledo», Revista de Filología Española, 56, (1973), pp. 229-328.

Dadson, Trevor J., «La poesía amorosa de los condes de Salinas y Villamediana: ¿Un diálogo subtextual?», en Manuel García Martín (ed.), Estado actual de los estudios sobre el Siglo de Oro: Actas del II Congreso de la AISO, Salamanca, Universidad de Salamanca, 1993, 2 vols., I, pp. 269-277.

Dadson, Trevor J., «La biblioteca del poeta y político Diego de Silva y Mendoza, Conde de Salinas (1564-1630)», Journal of Hispanic Research, 3, (1994-95), pp. 181-216.

Dadson, Trevor J., Libros, lectores y lecturas: Estudios sobre bibliotecas particulares españolas del Siglo de Oro, Madrid, Arco/Libros, 1998.

Dadson, Trevor J., «Editing the Poetry of Diego de Silva y Mendoza, Count of Salinas and Marquis of Alenquer», Bulletin of Hispanic Studies, 85, (2008), pp. 285-331.

Dadson, Trevor J., «Los libros y lecturas de un poeta áureo: don Diego de Silva y Mendoza, conde de Salinas», en Anne Cayuela et Laurie-Anne Laget (eds.), De la bibiothèque interieure a la bibliothèque collective: livres et lectures en Espagne (XVIe-XXIe siècles), Revue ILCEA, 25, (2016), 20 pp.

Dadson, Trevor J., «"Um Viso-Rei que faz trovas”. El conde de Salinas, Diego de Silva y Mendoza: mecenazgo poético y político entre Madrid y Lisboa», Atalante. Revista de las Letras Barrocas, (2019).

Dadson, Trevor J., La correspondencia politica de un virrey. Las cartas enviadas desde Lisboa (1617-1622) por Diego de Silva y Mendoza, marqués de Alenquer [en prensa].

Danvila y Burguero, Alonso, Don Cristóbal de Moura: 1538-1613, Madrid, Academia de la Historia, 1900.

Eisenberg, Daniel, «Did Cervantes Have a Library?», Hispanic Studies in Honor of Alan D. Deyermond. A North American Tribute, Madison, Wisconsin, Hispanic Seminary of Medieval Studies, 1986, pp. 93-106. 
Eisenberg, Daniel, «La biblioteca de Cervantes», Studia in honorem prof. M. de Riquer, Barcelona, Quaderns Crema, 1987, 3 vols., II, pp. 271-328.

Fernández González, Carlos y Sofía Simoes, «Nuevas Aportaciones a la biblioteca de Francisco de Quevedo», Manuscrt. Cao, 11, (2011), 54 pp.

Fernández González, Carlos y Sofía Simoes, «Apéndice a Nuevas Aportaciones a la biblioteca de Francisco de Quevedo», Manuscrt. Cao, 12, (2012), 11 pp.

Gaillard, Claude, «Un inventario de las poesías atribuidas al Conde de Salinas», Criticón, 41, (1988), pp. 5-66.

Glaser, Edward, «HVM VISO-REI QVE FAZ TROVAS. New Data on Don Diego de Silva y Mendoza, Poet and Statesman», en Homenaje. Estudios de filología e historia literaria lusohispanas e iberamericanas publicados para celebrar el tercer lustro del Instituto de Estudios Hispánicos, Portugueses e Iberoamericanos de la Universidad Estatal de Utrecht, La Haya, Van Goor Zonen, 1966, pp. 217-240.

Glaser, Edward (ed.), The Cancionero «Manuel de Faria». A critical edition with introduction and notes, Münster Westfalen, Aschendorffsche Verlagbuchhandlung, 1968.

Hurtado de Mendoza, Diego, Poesía completa, edición de José Ignacio Díez Fernández, Madrid, Fundación José Manuel Lara, 2007.

Malcolm, Alistair, Royal Favouritism and the Governing Elite of the Spanish Monarchy, 1640-1665, Oxford, University Press, 2017.

Maldonado, Felipe C. R., «Algunos datos sobre la composición y dispersión de la biblioteca de Quevedo», en Homenaje a la memoria de don Antonio RodríguezMoñino, Madrid, Castalia, 1975, pp. 405-428.

Manrique Martínez, Jorge, «Para la edición de la poesía del Conde de Salinas», en Manuel García Martín (ed.), Estado actual de los estudios sobre el Siglo de Oro: Actas del II Congreso de la AISO, Salamanca, Universidad de Salamanca, 1993, 2 vols., II, pp. 611-619.

Martínez Hernández, Santiago, «D. Cristóvão de Moura e a Casa dos Marqueses de Castelo Rodrigo. Proposta de investigação e linhas de análise sobre a figura do grande privado de D. Filipe I», en Santiago Martínez Hernández (dir.), Governo, Política e Representações do Poder no Portugal Habsburgo e nos seus Territórios Ultramarinos (1581-1640), Lisboa, Centro de História de Além-Mar, 2011, pp. 69-96.

Pérez Cuenca, Isabel, «Las lecturas de Quevedo a la luz de algunos impresos de su biblioteca», La Perinola, 7, (2003), pp. 297-333.

Pérez Cuenca, Isabel, «La reconstrucción de la biblioteca hipotética de Francisco de Quevedo. Viejos problemas y nuevos hallazgos», Analecta Malacitana, 38 (1-2), (2015), pp. 7-53.

Rodríguez Marín, F., Luis Barahona de Soto, estudio biográfico, bibliográfico y crítico, Madrid, 1903. 
Rosales, Luis, «La poesía cortesana», en Studia Philologica. Homenaje ofrecido a Dámaso Alonso, Madrid, Gredos, 1963, 3 vols., III, pp. 287-335.

Rosales, Luis, «Garcilaso, Camoens y la lírica española del Siglo de Oro», en Lírica española, Madrid, Editora Nacional, 1972, pp. 9-140.

Rosales, Luis, «La estimación literaria del conde de Salinas», en Studia Hispánica in honorem R. Lapesa, Madrid, Gredos, 1974, 3 vols., II, pp. 531-547.

Rozas, Juan Manuel (ed.), Cancionero de Mendes Britto. Poesías inéditas del conde de Villamediana, Madrid, CSIC, 1965.

Ruiz Pérez, Pedro y Ana Rojas Pérez, Libros y lecturas de un poeta humanista. Fernando de Herrera (1534-1597), Universidad de Córdoba, Servicio de Publicaciones, 1997.

Schwartz, Lia, "Las preciosas alhajas de los entendidos: Un humanista madrileño del siglo XVII y la difusión de los clásicos», Edad de Oro, 17, (1998), pp. 213-230.

Schwartz, Lia e Isabel Pérez Cuenca, «Unas notas autógrafas de Quevedo en un libro desconocido de su biblioteca», Boletín de la Real Academia Española, 79, (1999), pp. 67-91.

Silva y Mendoza, Diego de, conde de Salinas, Antología poética 1564-1630, edición de Trevor J. Dadson, Madrid, Visor, 1985.

Silva y Mendoza, Diego de, conde de Salinas, Obra completa. I. Poesía desconocida, edición de Trevor J. Dadson, Madrid, Real Academia Española, Anejos de la Biblioteca Clásica, 2016. 